\title{
Pengujian Kinerja Pompa Sentrifugal Multistage Berkapasitas 118,5 KW pada PLTP Berdasarkan Standar ISO 9906
}

\author{
Wahyu Hidayat, Damawidjaya Biksono, Dadan Zulpian \\ ${ }^{1}$ Jurusan Teknik Mesin, Universitas Jenderal Achmad Yani, Bandung-Cimahi, Indonesia \\ Email: wahyu.hidayat@lecture.unjani.ac.id
}

Received 8 Juli $2021 \mid$ Revised 12 Juli $2021 \mid$ Accepted 21 Juli 2021

\begin{abstract}
ABSTRAK
Pengujian unjuk kerja pompa sentrifugal multistage berkapasitas 118,5 kW di kawasan Pembangkit Listrik Tenaga Panas Bumi (PLTP) daerah Jawa Barat saat ini akan menyesuaikan prosedur standar. Standar pengujian pompa diterapkan pada proses pengujian pompa dengan tujuan nilai hasil pengujian valid. Nilai head dan debit yang didapat dari pengujian dibandingkan dengan hasil pengujian sebelum penerapan standar. Pengujian pompa sentrifugal menerapkan metode pengujian lapangan dengan menerapkan standar ISO 9906-2012. Standar ISO 9906-2012 adalah panduan baku pengujian pompa rotodinamik. Dari hasil pengujian, didapatkan kurva pompa sentrifugal multistage debit maksimal 116,64 $\mathrm{m}^{3} / \mathrm{jam}$ pada head 275,13 m. Pada data spesifikasi kapasitas pompa sebesar $108 \mathrm{~m}^{3} / \mathrm{jam}$ dan head total sebesar $300 \mathrm{~m}$. Hal ini berarti prosedur pengujian pompa ISO 9906-2012 dapat memungkinkan kita untuk melihat kinerja pompa aktual.
\end{abstract}

Kata kunci: pompa sentrifugal, pengujian lapangan, uji kinerja pompa, ISO 9906

\begin{abstract}
Performance test of multistage centrifugal pump at geothermal power plant area around west java is about to adapt standard procedure. Pump testing standards are applied during pump performance test in order to valid test result values. Head and flowrate value from current test compared with previous test result before standard are applied. Pump performance test use field test method by applying ISO 9906-2012 standard. ISO 9906-2012 standard is a normative guidance for rotodynamic pump testing. The test result shows multistage centrifugal pump curve maximum flowrate is $116,64 \mathrm{~m}^{3} / \mathrm{h}$ at total head $275,13 \mathrm{~m}$. Pump specification sheet shows that maximum capacity is $108 \mathrm{~m}^{3} / \mathrm{h}$ and total head $300 \mathrm{~m}$. It indicates that ISO 9906-2012 standard pump testing procedure allow us to determine actual pump performance.
\end{abstract}

Kata kunci: Centrifugal pump, field test, performance test, ISO 9906 


\section{PENDAHULUAN}

Sumber energi tidak terbarukan seperti minyak bumi, gas alam, dan batu bara yang dibutuhkan untuk memenuhi kebutuhan energi jumlahnya semakin menipis. Diperlukan sumber energi baru terbarukan yang lebih ramah terhadap pencemaran lingkungan atau peningkatan efisiensi untuk sistem yang sudah ada dalam pemanfaatan energi [1]. Peningkatan efisiensi untuk sistem bisa dilakukan dengan cara Combined Heat and Power (CHP) [2]. CHP merupakan teknologi yang digunakan untuk menghasilkan energi termal selain energi utama yang berupa energi listrik [3]. Salah satu sumber energi baru dan terbarukan adalah Pembangkit Listrik Tenaga Panas bumi (PLTP). Indonesia memiliki potensi panas bumi yang besar yaitu sebesar 28.617 MW [4]. Potensi ini membentang pada jalur cincin api dari Pulau Sumatera, Pulau jawa, Pulau Bali hingga Indonesia bagian timur [5]. Energi panas bumi yang telah dimanfaatkan sebagai pembangkit listrik terpasang di Indonesia sebesar 1.340 MWe [6].

Salah satu komponen utama yang terdapat di PLTP adalah pompa sentrifugal. Pompa sentrifugal merupakan salah satu jenis pompa yang paling banyak digunakan didunia, pemilihan jenis pompa ini berdasarkan kelebihan yang dimiliki oleh pompa sentrifugal yaitu prinsip kerja yang sederhana, telah teruji secara seksama, kuat, efektif dan biaya produksi yang tidak mahal [7]. Pompa sentrifugal digunakan di berbagai bidang industri dan dianggap sebagai komponen terpenting dalam setiap proses kerja sehingga kehandalannya mendapat bagian penting dari suatu proses bisnis [8].

Dalam proses pengeboran sumur produksi di lapangan kerja panas bumi, penggunaan pompa banyak digunakan pada proses pasokan air, injeksi air kedalam sumur dan pemindahan lumpur. Pengujian pompa sebelum aktifitas pengeboran dilakukan untuk memeriksa kehandalan dan menentukan kinerja aktual yang mampu dicapai. Evaluasi terhadap prestasi kerja pompa penting dilakukan untuk menentukan area aman operasi [7] untuk meyakinkan pengujian pompa dilakukan dengan baik, metode standar pengujian diterapkan. Grist dan Hentschke pada tahun 1990 menggunakan metode pengujian pompa sentrifugal yang mengacu pada standar BS-5316 (ISO 3555). Metode tersebut dilakukan untuk menentukan batas minimal dan maksimal operasi pompa [9]

Pengujian pompa sentrifugal multistage berkapasitas $118,5 \mathrm{~kW}$ di area kerja PLTP kawasan Jawa Barat saat ini akan diharmonisasikan dengan standar pengujian pompa sentrifugal. Standar ISO 9906 dijadikan prosedur standar normatif pengujian untuk mengetahui nilai prestasi dari suatu pompa rotodinamik yang terpasang. Tujuan penelitian ini adalah penerapan prosedur standar ISO 9906 pada pengujian pompa sentrifugal multistage berkapasitas $118,5 \mathrm{~kW}$ kemudian membandingkan hasil pengujian debit dan head dengan data pengujian sebelum penerapan standar ISO 9906. Hasil pengujian unjuk kerja pompa dengan penerapan standar ISO 9906 diharapkan lebih valid. Data hasil pengujian sebelum dan setelah penerapan standar ISO 9906 serta data ideal yang dikeluarkan oleh manufaktur pompa akan dibandingkan dalam kurva $\mathrm{H}-\mathrm{Q}$.

\section{METODOLOGI}

Metode penelitian yang digunakan pada penelitian ini adalah metode penelitian deskriptif-kuantitatif. Pada penelitian ini uraian penjelasan mengenai objek penelitian akan secara sistematis dipaparkan dan teori yang berhubungan dengan objek penelitian akan digunakan dan dipadukan agar hasil akhir berupa sajian data yang lebih menekankan pada pengolahan angka hasil pengukuran, tabel dan grafik. Pada stasiun pompa yang berada di lapangan PLTP, terdapat 4 pompa sentrifugal dengan spesifikasi yang identik dan terpasang secara paralel. Pompa sentrifugal multistage A \& B berpenggerak mula motor listrik, Pompa sentrifugal C \& D berpenggerak mula mesin diesel. Objek penelitian untuk analisa penelitian ini adalah pompa sentrifugal $\mathrm{D}$ berpenggerak mula mesin diesel. Pompa sentrifugal multistage D merupakan pompa sentrifugal dengan jumlah impeler sebanyak 4 buah dalam satu casing pompa dengan konfigurasi horizontal impeller bare shaft end. Berikut adalah spesifikasi dan data teknis instalasi perpipaan. 
Pengujian Kinerja Pompa Sentrifugal Multistage Berkapasitas 118,5 KW pada PLTP Berdasarkan Standar ISO 9906

Tabel 1. Spesifikasi pompa sentrifugal

\begin{tabular}{ll}
\hline Manufacturer & OSNA Pumpen Technologie \\
\hline Model & NMH 32-80 \\
\hline Type & $\begin{array}{l}\text { Horizontal Multi Stage } \\
\text { Bare shaft end }\end{array}$ \\
\hline Capacity & $108 \mathrm{~m}^{3} / \mathrm{jam}$ \\
\hline Total Head & $300 \mathrm{~m}$ \\
\hline NPSHR & $3,3 \mathrm{~m}$ \\
\hline Power Input at pump shaft & $118,5 \mathrm{~kW}$ \\
\hline Motor Capacity Required & $132 \mathrm{~kW}$ \\
\hline Efficiency & $69 \%$ \\
\hline No. of Stages & 4 \\
\hline Guarantee operational data & ISO 9906, Class 2 \\
\hline
\end{tabular}

Sumber: Fuji Electric Co., Ltd. (1999)

Tabel 2. Spesifikasi instalasi pipa dan data lingkungan

\begin{tabular}{|c|c|}
\hline \multicolumn{2}{|l|}{ 1. Spesifikasi Pipa } \\
\hline Diameter & 8' 'DN200 SCH 40 dengan diameter dalam pipa discharge $\left(\mathrm{d}_{\mathrm{d}}\right) 0,202715$ meter \\
\hline Material & Carbon Steel (terkorosi) $\varepsilon=0,15 \mathrm{~mm}$ \\
\hline \multicolumn{2}{|c|}{ 2. Instalasi pipa suction } \\
\hline Panjang & Panjang pipa carbon steel jalur discharge $\left(\mathrm{L}_{\mathrm{d}}\right) 307$ meter \\
\hline Katup dan Fitting & $\begin{array}{l}10 \text { buah } 90^{\circ} \text { smooth bend (flanged) ukuran } 8 ",(\mathrm{~K}=0,3) \\
5 \text { buah } 45^{\circ} \text { elbow (threaded) ukuran } 8 "(\mathrm{~K}=0,2) \\
2 \text { buah pipe inlet (well rounded) ukuran } 8 "(\mathrm{~K}=0,5) \\
3 \text { buah pipe exit (rounded) ukuran } 8 "(\mathrm{~K}=1) \\
7 \text { buah katup jenis gate valve (fully open) ukuran } 8 "(\mathrm{~K}=0,15)\end{array}$ \\
\hline \multicolumn{2}{|c|}{ 3. Instalasi pipa discharge } \\
\hline Panjang & Panjang pipa carbon steel jalur discharge $\left(\mathrm{L}_{\mathrm{s}}\right) 107,9$ meter \\
\hline Katup dan Fitting & $\begin{array}{l}4 \text { buah elbow } 90^{\circ}(\mathrm{K}=0,3) \\
7 \text { buah long radius elbow } 45^{\circ}(\mathrm{K}=0,2) \\
3 \text { buah gate valve }(\mathrm{K}=0,15) \\
1 \text { buah tee branch flow }(\mathrm{K}=1) \\
1 \text { buah globe valve }(\mathrm{K}=10) \\
1 \text { buah pipa inlet sharp edge }(\mathrm{K}=0,5) \\
1 \text { buah pipa outlet sharp edge }(\mathrm{K}=1) \\
1 \text { buah bucket strainer }(\mathrm{K}=2)\end{array}$ \\
\hline \multicolumn{2}{|c|}{ 4. Cairan Yang Digunakan } \\
\hline Jenis & Air \\
\hline Temperatur & $20^{\circ} \mathrm{C}$ \\
\hline Massa Jenis & $998,2 \mathrm{~kg} / \mathrm{m}^{3}$ \\
\hline $\begin{array}{l}\text { Viskositas Dinamik } \\
(\mu)\end{array}$ & $0,001002 \mathrm{~kg} / \mathrm{m} . \mathrm{s}$ \\
\hline Berat Spesifik $(\gamma)$ & $9,789 \mathrm{kN} / \mathrm{m}^{3}$ \\
\hline $\begin{array}{l}\text { Ketinggian dari } \\
\text { permukaan laut }\end{array}$ & Kolam penampungan: $1631 \mathrm{mdpl}$, Pompa: $1620 \mathrm{mdpl}$ \\
\hline Tekanan udara & 0,827 bara atau $82700 \mathrm{~N} / \mathrm{m}^{2}$ \\
\hline $\begin{array}{l}\text { Elevasi muka air } \\
\text { terhadap datum }\end{array}$ & - $11 \mathrm{~m}$ (bernilai negatif karena reservoar air berada diatas pompa) \\
\hline
\end{tabular}




\subsection{Tahapan Penelitian}

Sebelum dilakukan pengujian pompa, terdapat beberapa tahapan validasi. Data spesifikasi pompa yang terdapat pada Tabel 1 diolah untuk mencari kecepatan spesifik dan jenis impeller pompa. Perhitungan validasi pompa dilakukan untuk memastikan pompa sesuai dengan kondisi pemompaan setempat. Nilai NPSH pada kondisi aktual dihitung untuk memastikan syarat pompa tidak mengalami kavitasi $\left(\mathrm{NPSH}_{\mathrm{A}}\right.$ $>\mathrm{NPSH}_{\mathrm{R}}$ ). Kavitasi adalah suatu fenomena timbulnya gelembung-gelembung udara dalam fluida akibat turunnya tekanan fluida dalam pompa melebihi tekanan dibawah uap jenuh fluida tersebut, sehingga ketika kondisi tekanan fluida turun dibawah tekanan uap jenuh ( $\mathrm{P}<$ Psat) maka timbul uap dalam bentuk gelembung udara. Fenomena kavitasi harus dihindari (atau setidaknya diminimalkan) dalam sistem aliran karena mengurangi unjuk kerja, menimbulkan getaran dan kebisingan yang mengganggu, dan menyebabkan kerusakan pada pompa. Lonjakan tekanan yang dihasilkan dari sejumlah besar gelembung yang runtuh didekat permukaan padat selama jangka waktu yang lama dapat menyebabkan erosi, permukaan berlubang, kegagalan fatigue, dan akhirnya kerusakan komponen atau mesin.

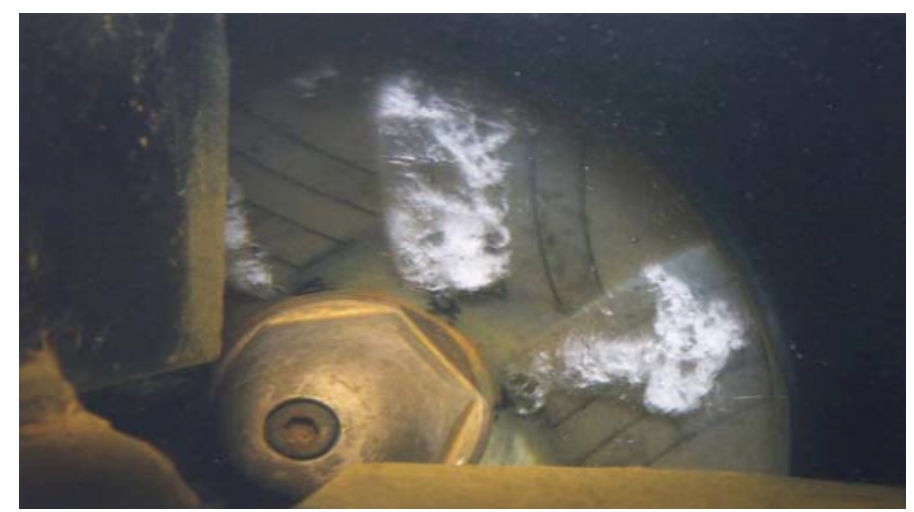

Gambar 1. Kavitasi pada impeler

Penelitian ini memiliki tujuan mengetahui prestasi unjuk kerja pompa sentrifugal Thermal Pond D. Pada sistem pembangkit listrik panas bumi di Star Energi Geothermal Wayang Windu Ltd terdapat kolam penampungan yang dinamakan dengan Thermal Pond. Kolam tersebut merupakan kolam penampungan utama yang digunakan untuk menampung Liquid Geothermal Effluent (LGE) atau limbah cair panas bumi yang dihasilkan selama proses eksploitasi sumur uap panas bumi selama proses pembangkitan listrik berlangsung. LGE terdiri dari brine, kondensat dan semua air drainase dari power station. Air yang terdapat pada thermal pond dimanfaatkan sebagai sumber air untuk keperluan aktivitas panas bumi seperti kegiatan perawatan sumur uap, pengeboran sumur uap dan mempertahankan aliran minimal sumur injeksi.

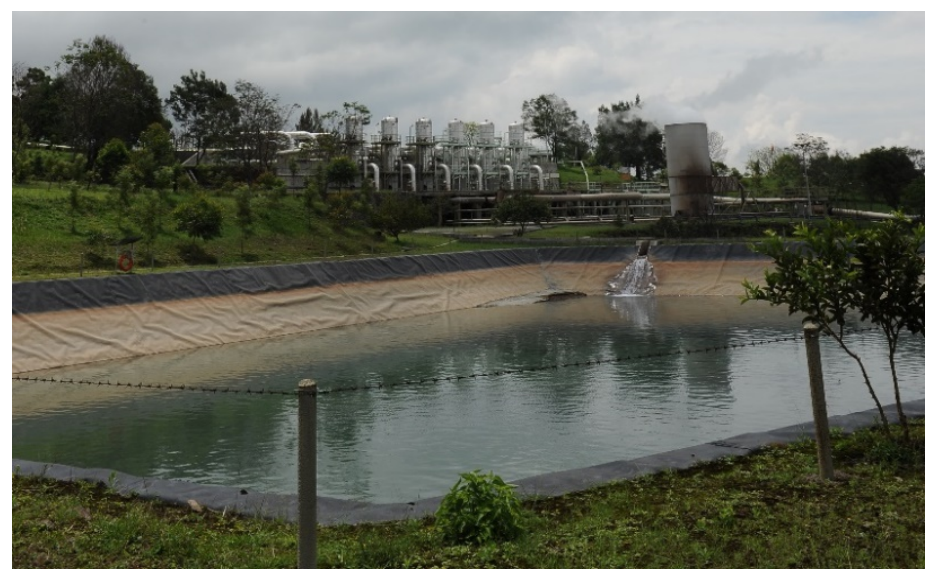

Gambar 2. Thermal pond PLTP

Uraian penjelasan mengenai objek penelitian lebih menekankan pada pengolahan angka hasil pengukuran, tabel dan grafik sehingga objektifitas hasil penelitian dapat dicapai, sistematis, terperinci, 
jelas dan mampu hitung. Kajian penelitian ini disertakan pula panduan standar uji kinerja pompa sentrifugal ISO 9906-2012 Rotodynamic Pumps - Hydraulic Performance Acceptance Tests Grades 1,2 \& 3. Panduan tersebut digunakan sebagai acuan induk dalam penetapan hasil uji terhadap data teknis yang dimiliki oleh pompa dari manufaktur pembuat pompa. Deviasi nilai antara hasil uji dengan data spesifikasi teknis pompa akan diukur prosentasenya dan disesuaikan pada tingkatan prosentase toleransi yang terdapat panduan standar ISO 9906. Berdasarkan panduan standar ISO, nilai uji parameter yang akan diketahui yaitu head $(\mathrm{H})$ dan debit (Q). Seluruh alat ukur yang digunakan dilakukan kalibrasi sebelum pengujian dilakukan. Variabel bebas yang digunakan yaitu bukaan katup discharge dengan kondisi bukaan $20 \%, 40 \%, 60 \%, 80 \%$ dan $100 \%$ bukaan penuh. Kelima kondisi bukaan katup tersebut disesuaikan dengan point prosedur ISO 9906 poin 5.7.1. Setelah data pengujian didapat kemudian data diolah untuk menentukan head loss total pada sisi suction dan discharge. Nilai debit dan nilai head loss total selanjutnya divisualisasikan kedalam diagram kartesian dua sumbu sehingga kurva karakteristik H-Q terbentuk. Data hasil pengujian sebelum penerapan standar ISO-9906 dibandingkan untuk dilakukan analisa dan menyimpulkan hasil pengujian berdasarkan standar ISO 9906-2012.

\subsection{Kalibrasi Alat Ukur}

Untuk memastikan pembacaan alat ukur saat pengujian pompa sentrifugal akurat diperlukan kalibrasi pada setiap alat ukur yang terpasang pada pompa. Dalam ISO 9906:2012 nilai fluktuasi alat ukur ditentukan rentang nilai maksimal dan minimalnya dan dirata-ratakan berdasarkan pada tingkatan atau grade. Berikut adalah tabel fluktuasi pembacaan yang diizinkan yang terdapat pada Tabel 3 dalam ISO 9906:2012.

Tabel 3. Persentase fluktuasi pembacaan alat ukur yang diizinkan

\begin{tabular}{lrrr}
\hline \multirow{2}{*}{ Measured quantuty } & \multicolumn{2}{c}{ Permissible amplitude of fluctuations } \\
\cline { 2 - 4 } & Grade 1 (\%) & Grade 2 (\%) & Grade 3 (\%) \\
\hline Rateof flow & \pm 2 & \pm 3 & \pm 6 \\
\hline Differential head & \pm 3 & \pm 4 & \pm 10 \\
\hline Outlet head & \pm 2 & \pm 3 & \pm 6 \\
\hline Inlet head & \pm 2 & \pm 3 & \pm 6 \\
\hline Input power & \pm 2 & \pm 3 & \pm 6 \\
\hline Speed of rotation & \pm 0.5 & \pm 1 & \pm 2 \\
\hline Torque & \pm 2 & \pm 3 & \pm 6 \\
\hline Temperature & $0,3^{\circ} \mathrm{C}$ & $0,3^{\circ} \mathrm{C}$ & $0,3^{\circ} \mathrm{C}$ \\
\hline
\end{tabular}

Pada proses penelitian ini, terdapat beberapa jenis alat ukur yang digunakan untuk membaca parameter uji pada pompa yaitu pressure gauge, ultrasonic flowmeter, orifice flowmeter dan tachometer.

\subsubsection{Pressure Gauge}

Untuk mengukur tekanan pada sisi suction (isapan) dan sisi discharge (keluaran) pompa pada instalasi uji penelitian digunakan pressure gauge dengan jenis bourdon tube. Pressure gauge yang terpasang pada sisi suction adalah merek Wika dengan rentang pembacaan hingga 5 Bar. Untuk sisi discharge pressure gauge adalah merek Schuh Technology dengan rentang pembacaan hingga 60 Bar. Pada pressure gauge jenis bourdon tube terdapat pipa lengkung dimana salah satu ujung terhubung dengan pipa aliran fluida sebagai saluran masuk sampel dan ujung lainnya tertutup. Saat sampel fluida bertekanan masuk maka tabung ini akan meregang. Perubahan regangan sesuai dengan besarnya tekanan sampel fluida. Perubahan regangan ini dihubungkan pada roda gigi dan jarum dial. Perubahan jarum (dial) diikuti dengan skala pembacaan yang dituliskan. Kalibrasi alat ukur tekanan pressure gange ini yaitu dengan memasangnya pada instalasi kalibrator dan membandingkan hasil pembacaan dengan alat ukur lain yang sudah terstandarisasi. Metode kalibrasi pressure gauge ini adalah memberi sampel fluida bertekanan yang sama pada kalibrator dan alat ukur yang akan di kalibrasi. Masukan di mulai dari $0 \%$ 
skala hingga mencapai $100 \%$ skala dengan kenaikan $20 \%$ skala, kemudian diturunkan dengan cara yang sama hingga mencapai 0\% skala kembali. Penyimpangan atau deviasi yang terjadi dicatat. Jika hasil pemeriksaan kalibrasi melebihi toleransi, dilakukan penyetelan dengan memutar sekrup kecil pada bagian belakang pressure gauge.

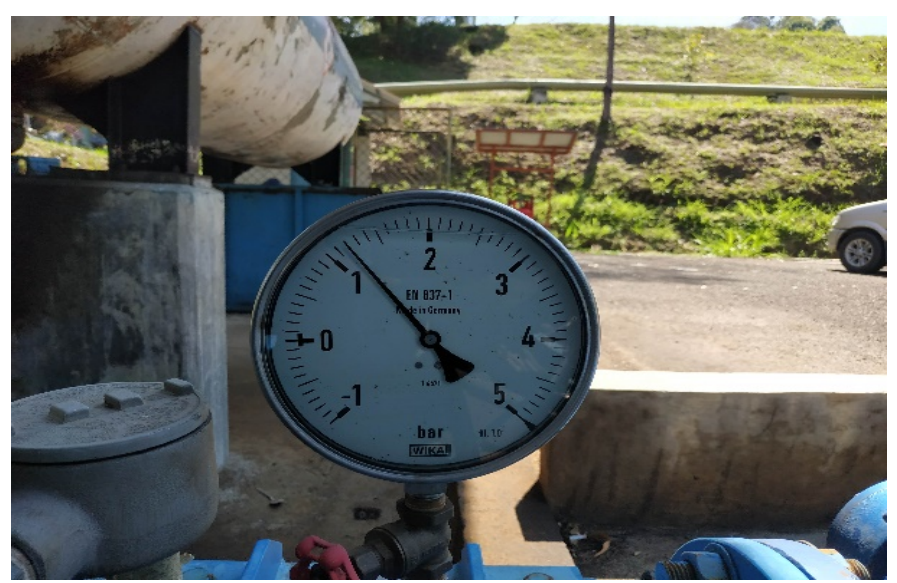

Gambar 3. Pressure gauge jenis bourdon pada sisi suction

\subsubsection{Flowmeter}

Pada penelitian ini untuk pengukuran laju aliran fluida dalam pipa menggunakan dua jenis flowmeter yaitu ultrasonic dan plat orifice. Ultrasonic flowmeter bersifat portable sehingga dapat digunakan pada titik yang dikehendaki dan untuk plat orifice terpasang pada instalasi pipa secara permanen. Ultrasonic flowmeter adalah merek GE TransPort PT878. Untuk plat orifice adalah merek Fuji electric.

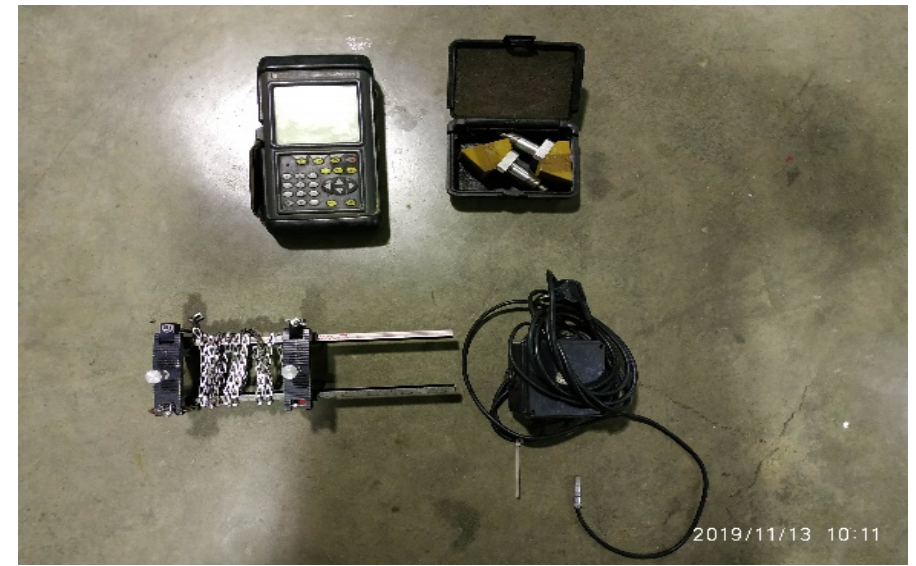

Gambar 4. Perangkat ultrasonic flowmeter GE transPort PT878

Dalam penelitian ini alat ukur laju aliran yang dijadikan acuan pembacaan adalah flowmeter ultrasonic. Alat ukur aliran ini bekerja dengan membangkitkan gelombang suara melalui transduser dan mengukur perambatan sinyal-sinyal melalui aliran fluida. Kalibrasi ultrasonic flowmeter dilakukan setiap 2 tahun sekali dan dilakukan oleh pihak ketiga. Selama periode tersebut alat ukur dinyatakan valid dalam pembacaan data. Ultrasonic flowmeter memiliki riwayat kalibrasi terakhir pada 21 Mei 2018.

\subsubsection{Tachometer}

Untuk pengukuran kecepatan putaran poros pompa digunakan laser tachometer. Tachometer yang digunakan pada penelitian ini adalah merek VIBXpert yang dapat digunakan pula untuk mengukur getaran. Alat ukur ini menggunakan sinar inframerah untuk mendeteksi putaran permukaan poros. Sinar yang mengenai permukaan poros yang berputar direfleksikan kembali pada penerima sinyal pada 
tachometer. Pantulan sinar inframerah menghasilkan perubahan frequensi. Sinar dengan perubahan frekuensi tersebut terbaca oleh penerima sinyal dan dikonversikan menjadi putaran. Sama seperti ultrasonic flowmeter, kalibrasi tachometer dilakukan oleh pihak ketiga yang merupakan vendor alat.

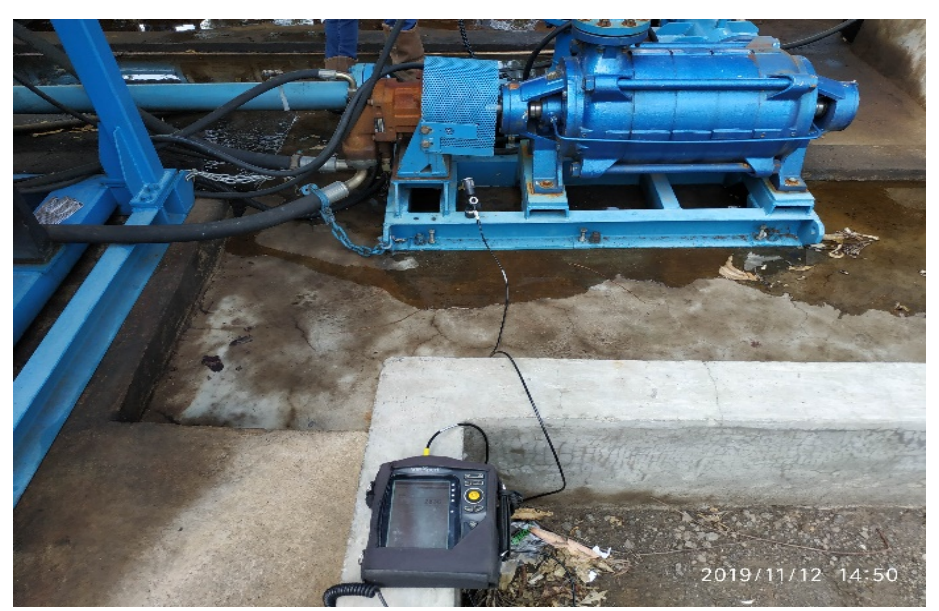

Gambar 5. Instalasi pemasangan tachometer

\subsection{Instalasi Pompa Sentrifugal}

Sistem distribusi air pada wilayah PLTP termasuk kedalam Non Potable Water Recirculating System (NPWRS). NPWRS pada PLTP merupakan jalur perpipaan lapangan yang menghubungkan antara kolam penampungan utama ke kolam penampungan pada masing-masing sumur uap. Berdasarkan Gambar 2, pada setiap sisi kolam penampungan utama, baik kolam sisi atas (upper) dan sisi bawah (lower) terdapat 2 jalur pipa berukuran 8 inchi Untuk pengujian pompa sentrifugal multistage D akan dilakukan secara siklus tertutup (closed loop) dimana air dari kolam penampungan sisi atas (upper) akan dipompakan pada jalur pipa yang mengarah kembali pada kolam penampungan sisi atas. Katup-katup yang berada pada jalur pipa NPWRS disesuaikan kondisi buka tutupnya, seperti pada Gambar 6 dibawah.

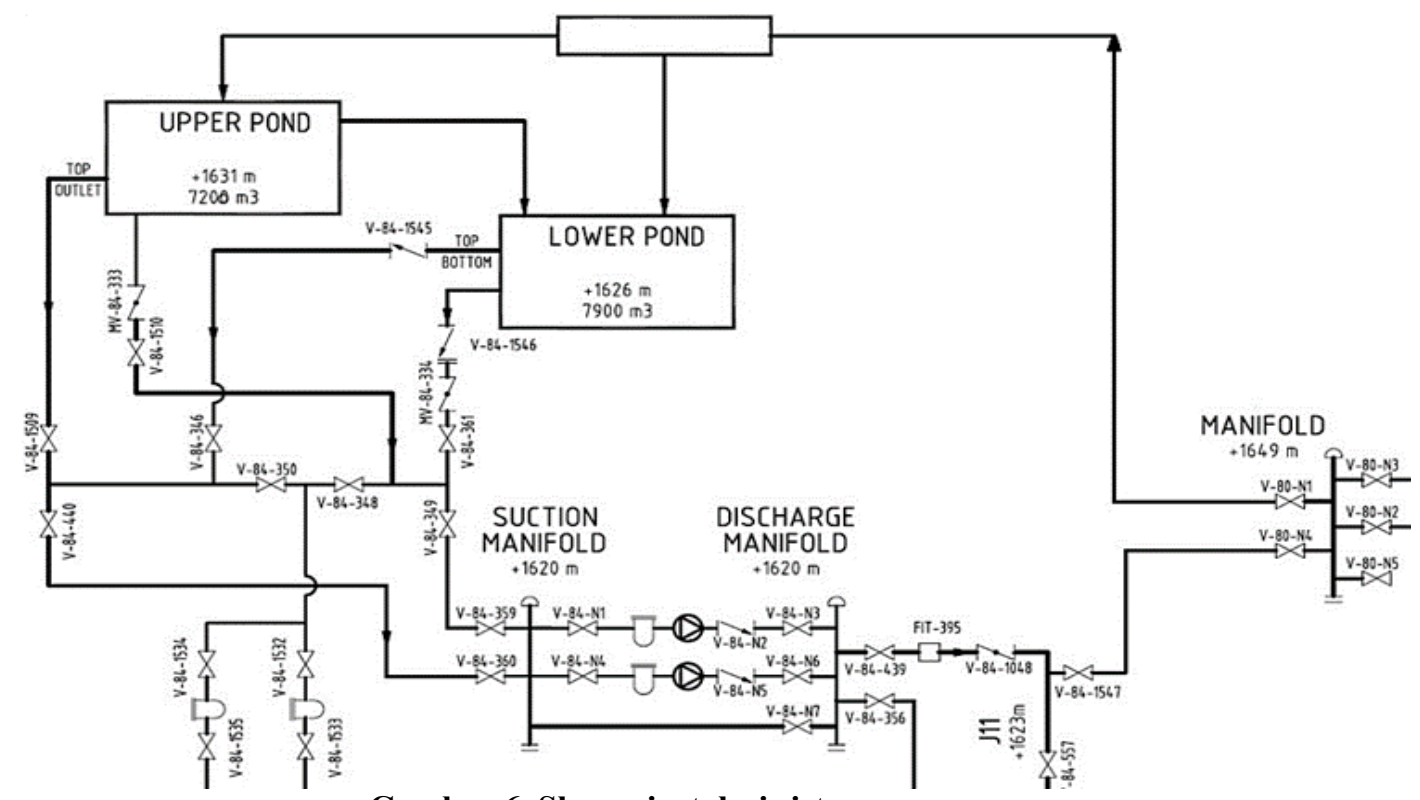

Gambar 6. Skema instalasi sistem pemompaan 


\subsection{Head Statis}

Head statis adalah perubahan elevasi total yang harus dilalui fluida cair. Head statis dapat diukur dari permukaan cairan di tanki isap ke permukaan cairan di dalam bejana tempat cairan dikirim. Head statis total diukur dari permukaan cairan di tanki isap ke permukaan cairan di bejana tempat cairan dikirim, terlepas dari apakah pompa terletak di atas level air di tanki isap atau berada di bawah level air tanki isap.

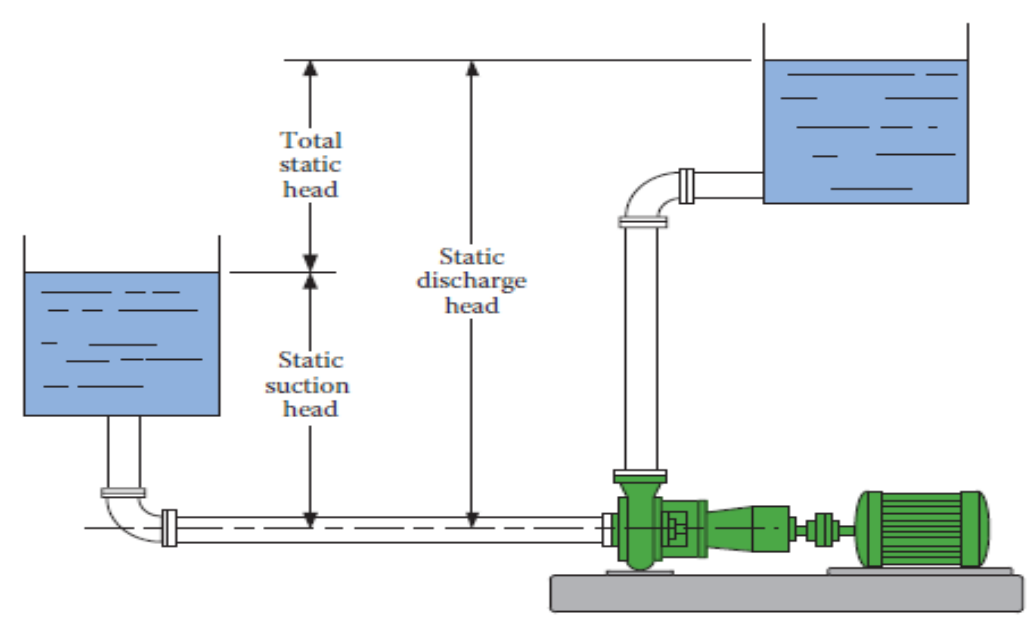

Gambar 7. Head statik pada instalasi pompa

Sehingga berdasarkan Gambar 3, head statis total pada pompa merupakan pengurangan dari static head discharge dengan static suction head. Perhitungan head statis (ha) dilakukan untuk mengetahui pengaruh beda ketinggian fluida yang berada pada kolam Thermal Pond terhadap pompa. Instalasi pompa sentrifugal terpasang lebih rendah daripada kolam Thermal Pond. Pada perhitungan ini dibutuhkan data elevasi muka air di sisi keluaran pompa terhadap datum (Zd) dan elevasi muka air di sisi isap terhadap datum $(\mathrm{Zs})$.

\subsection{Perhitungan Pompa} Kecepatan spesifik

Menghitung kecepatan spesifik menggunakan data spesifikasi pada Tabel 1 dan menggunakan Persamaan [10] :

$$
N_{s}=\frac{n Q^{1 / 2}}{H^{3 / 4}}
$$

\section{NPSH $_{A}$}

Pada penentuan $\mathrm{NPSH}_{\mathrm{A}}$ terdiri dari beberapa langkah perhitungan yaitu:

a. Luas Penampang $(A s)$

$$
A=\frac{1}{4} \pi d^{2}
$$


b. Reynold Number (Re)

$$
R e=\frac{v D}{\mu}=\frac{\rho V D}{\mu}
$$

Nilai bilangan Reynold kurang dari 2300 alirannya bersifat laminer. Untuk bilangan Reynold lebih besar dari 4000 alirannya bersifat turbulen serts untuk bilangan Reynold diantara 2300 dan 4000 maka terjadi aliran transisi, dimana pada aliran tersebut bersifat laminer atau turbulen [11].

c. Faktor gesekan $(f)$

Penentuan nilai faktor gesekan $(f)$ didapat dengan menggunakan diagram Moody. Pada penentuan nilai $(f)$ dan $(R e)$ Nilai kekasaran relatif $(\varepsilon)$ didapat dari Tabel 2, Carbon Steel (terkorosi) $\varepsilon=0,15 \mathrm{~mm}$.

d. Rugi-rugi mayor $\left(h_{f}\right)$

$$
h_{f}=f \frac{l}{D} \frac{V^{2}}{2 g}
$$

e. Rugi-rugi minor $\left(h_{L}\right)$

$$
h_{L}=K_{L} \cdot \frac{V^{2}}{2 g}
$$

Kavitasi dapat diminimalisir dengan cara mengkondisikan nilai $\mathrm{NPSH}_{\mathrm{A}}$ harus memiliki nilai lebih besar daripada $\mathrm{NPSH}_{\mathrm{R}}$. Harus dikondisikan tidak terdapat bagian dari flow di dalam pompa memiliki tekanan statis lebih keci dari tekanan uap jenuh cairan pada temperatur setempat. Untuk menghitung $\mathrm{NPSH}_{\mathrm{A}}$ menggunakan data spesifikasi instalasi pipa dan data lingkungan pada Tabel 1 dengan menggunakan persamaan :

$$
N P S H=H_{1}-Z_{S}+\frac{P_{a m b}-P_{v}}{\rho g}
$$

\subsection{Head Total}

Pada penentuan Head total terdiri dari beberapa langkah perhitungan yaitu:

a. Head kecepatan

$$
h_{V}=\frac{V_{d}^{2}-V_{s}^{2}}{2 g}
$$


b. Head tekanan

$$
h_{p}=\frac{p_{d}-p_{s}}{\gamma}
$$

c. Rugi-rugi mayor, menggunakan Persamaan (4)

d. Rugi-rugi minor, menggunakan Persamaan (5)

Nilai head total pada sisi suction dan sisi discharge ditentukan keduanya, masing-masing nilai head digunakan pada persamaan head total keseluruhan [10]:

$$
H_{\text {total }}=\left(Z_{d}-Z_{s}+\frac{p_{d}-p_{s}}{\rho g}+\frac{v_{d}^{2}-v_{s}^{2}}{2 g}\right)+\Sigma h_{f(d-s)}
$$

\section{HASIL DAN PEMBAHASAN}

Data-data pengujian dan pembacaan alat ukur disajikan pada Tabel 4. Data pada Tabel 5 adalah hasil perhitungan head total dengan menggunakan Persamaan (9). Grafik hubungan head dengan debit (HQ), ditunjukan pada Gambar 8. Data hasil pengujian pada tahun 2017, 2018 dan 2019 dimasukan pada satu kurva $\mathrm{H}-\mathrm{Q}$ yang sama dengan tujuan garis kurva dapat dibandingkan.

Tabel 4. Data hasil pengujian

\begin{tabular}{ccccc}
\hline $\begin{array}{c}\text { Bukaan katup } \\
\text { discharge (\%) }\end{array}$ & $\begin{array}{c}\text { Tekanan Isap } \\
\text { (Bar) }\end{array}$ & $\begin{array}{c}\text { Tekanan } \\
\text { Keluaran } \\
\text { (Bar) }\end{array}$ & \multicolumn{2}{c}{ Debit (lt/s) } \\
\hline 20 & 1,1 & 31.30 & 19,50 & 0.0195 \\
\hline 40 & 1,0 & 30,90 & 21,30 & 0.0213 \\
\hline 60 & 1,0 & 30,30 & 24,10 & 0.0241 \\
\hline 80 & 0,9 & 29,60 & 29,20 & 0.0292 \\
\hline 100 & 0,9 & 27,50 & 32,40 & 0.0324 \\
\hline
\end{tabular}

Tabel 5. Data hasil perhitungan setiap komponen head

\begin{tabular}{cccccccc}
\hline Bukaan katup discharge $(\mathbf{\%})$ & $\begin{array}{c}\mathbf{h}_{\mathbf{v}} \\
(\mathbf{m})\end{array}$ & $\begin{array}{c}\mathbf{h}_{\mathbf{p}} \\
(\mathbf{m})\end{array}$ & $\begin{array}{c}\mathbf{h}_{f \mathbf{d}} \\
(\mathbf{m})\end{array}$ & $\begin{array}{c}\mathbf{h}_{\mathbf{f s}} \\
(\mathbf{m})\end{array}$ & $\begin{array}{c}\mathbf{h}_{\mathrm{ld}} \\
(\mathbf{m})\end{array}$ & $\begin{array}{c}\mathbf{h}_{\mathrm{ls}} \\
(\mathbf{m})\end{array}$ & $\begin{array}{c}\mathbf{H}_{\text {tot }} \\
(\mathbf{m})\end{array}$ \\
\hline 20 & $-0,07$ & 308,40 & 0,59 & 0,21 & 0,18 & 0,33 & 309,70 \\
\hline 40 & $-0,07$ & 305,34 & 0,69 & 0,24 & 0,21 & 0,39 & 306,88 \\
\hline 60 & $-0,09$ & 299,21 & 0,88 & 0,31 & 0,27 & 0,50 & 301,17 \\
\hline 80 & $-0,07$ & 293,09 & 1,27 & 0,45 & 0,40 & 0,73 & 295,93 \\
\hline 100 & $-0,16$ & 271,64 & 1,55 & 0,54 & 0,49 & 0,90 & 275,13 \\
\hline
\end{tabular}

Berdasarkan informasi yang didapat dari Reliability Engineer PLTP setempat sebagai penyelenggara pengujian pompa, metode pengujian yang diterapkan pada tahun 2017 hingga 2019 yaitu secara sistem terbuka. Debit maksimum yang didapat pompa rata-rata yaitu $101,32 \mathrm{~m}^{3} / \mathrm{jam}$ dengan head sebesar 212 meter. Jalur pemompaan pada pengujian ini yaitu dari kolam penampungan utama menuju salah satu kolam 
pada sumur uap dengan jarak sejauh $3,2 \mathrm{~km}$. Kolam penampungan pada sumur uap berada pada ketinggian 1847 mdpl dan ketinggian kolam penampungan utama berada pada 1620 mdpl, sehingga selisih ketinggian yang antara kedua kolam adalah 227 meter. Data riwayat pengujian pompa hingga saat ini tersaji pada Tabel 6.

Tabel 6. Kompilasi data hasil pengujian

\begin{tabular}{|c|c|c|c|c|c|c|c|c|c|}
\hline \multirow{3}{*}{$\begin{array}{l}\text { Bukaan } \\
\text { katup } \\
\text { discharge } \\
\text { (\%) }\end{array}$} & \multicolumn{6}{|c|}{ Tanggal Pengujian } & \multirow{3}{*}{$\begin{array}{l}\text { Bukaan } \\
\text { katup } \\
\text { discharge } \\
(\%)\end{array}$} & \multirow{2}{*}{\multicolumn{2}{|c|}{$\begin{array}{c}\begin{array}{c}\text { Tanggal } \\
\text { Pengujian }\end{array} \\
12 \text { Desember } 2019\end{array}$}} \\
\hline & \multicolumn{2}{|c|}{29 Juli 2017} & \multicolumn{2}{|c|}{14 April 2018} & \multicolumn{2}{|c|}{11 September 2018} & & & \\
\hline & $\begin{array}{c}\text { Debit } \\
\left(\mathrm{m}^{3} / \mathrm{jam}\right)\end{array}$ & $\begin{array}{l}\text { Head } \\
(\mathrm{m})\end{array}$ & $\begin{array}{c}\text { Debit } \\
\left(\mathrm{m}^{3} / \mathrm{jam}\right)\end{array}$ & $\begin{array}{l}\text { Head } \\
(\mathrm{m})\end{array}$ & $\begin{array}{c}\text { Debit } \\
\left(\mathrm{m}^{3} / \mathrm{jam}\right)\end{array}$ & $\begin{array}{l}\text { Head } \\
(\mathrm{m})\end{array}$ & & $\begin{array}{c}\text { Debit } \\
\left(\mathrm{m}^{3} / \mathrm{jam}\right)\end{array}$ & $\begin{array}{l}\text { Head } \\
\text { (m) }\end{array}$ \\
\hline 25 & 47,92 & 303,65 & 52,13 & 302,67 & 50,36 & 300,23 & 20 & 70,20 & 309,70 \\
\hline 50 & 74,41 & 270,02 & 71,57 & 273,64 & 68,47 & 274,98 & 40 & 76,68 & 306,88 \\
\hline 75 & 90,83 & 240,12 & 94,86 & 230,71 & 96,01 & 231,35 & 60 & 86,76 & 301,17 \\
\hline 100 & 97,60 & 212,14 & 103,54 & 213,57 & 102,82 & 211,57 & 80 & 105,12 & 295,93 \\
\hline & & & & & & & 100 & 116,64 & 275,13 \\
\hline
\end{tabular}

Dari hasil pengujian tanggal 12 Desember 2019, nilai head maksimum yang dapat dicapai pompa yaitu pada nilai 309,7 m pada pengaturan katup bukaan discharge sebesar 20\%. Kapasitas debit (Q) maksimal didapat pompa pada bukaan $100 \%$ sebesar $116,64 \mathrm{~m}^{3} / \mathrm{jam}$. Apabila dibandingkan dengan data spesifikasi pada Tabel 1, kapasitas pompa yang diterbitkan oleh manufaktur pompa sebesar $108 \mathrm{~m}^{3} / \mathrm{jam}$. Data hasil pengujian dengan data spesifikasi memiliki selisih sebesar $8,64 \mathrm{~m}^{3} / \mathrm{jam}$. Untuk nilai head yang tercantum pada data spesifikasi Tabel 1, tertulis total head pada kapasitas $108 \mathrm{~m}^{3} / \mathrm{jam}$ sebesar $300 \mathrm{~m}$. Pada data hasil pengujian nilai head yang didapat pada kondisi $100 \%$ bukaan katup discharge pompa yaitu 275,13 m. Data hasil pengujian dengan data spesifikasi memiliki selisih sebesar 24,87 meter. Sehingga nilai head dan debit data hasil pengujian disajikan pada kurva H-Q pada Gambar 8.

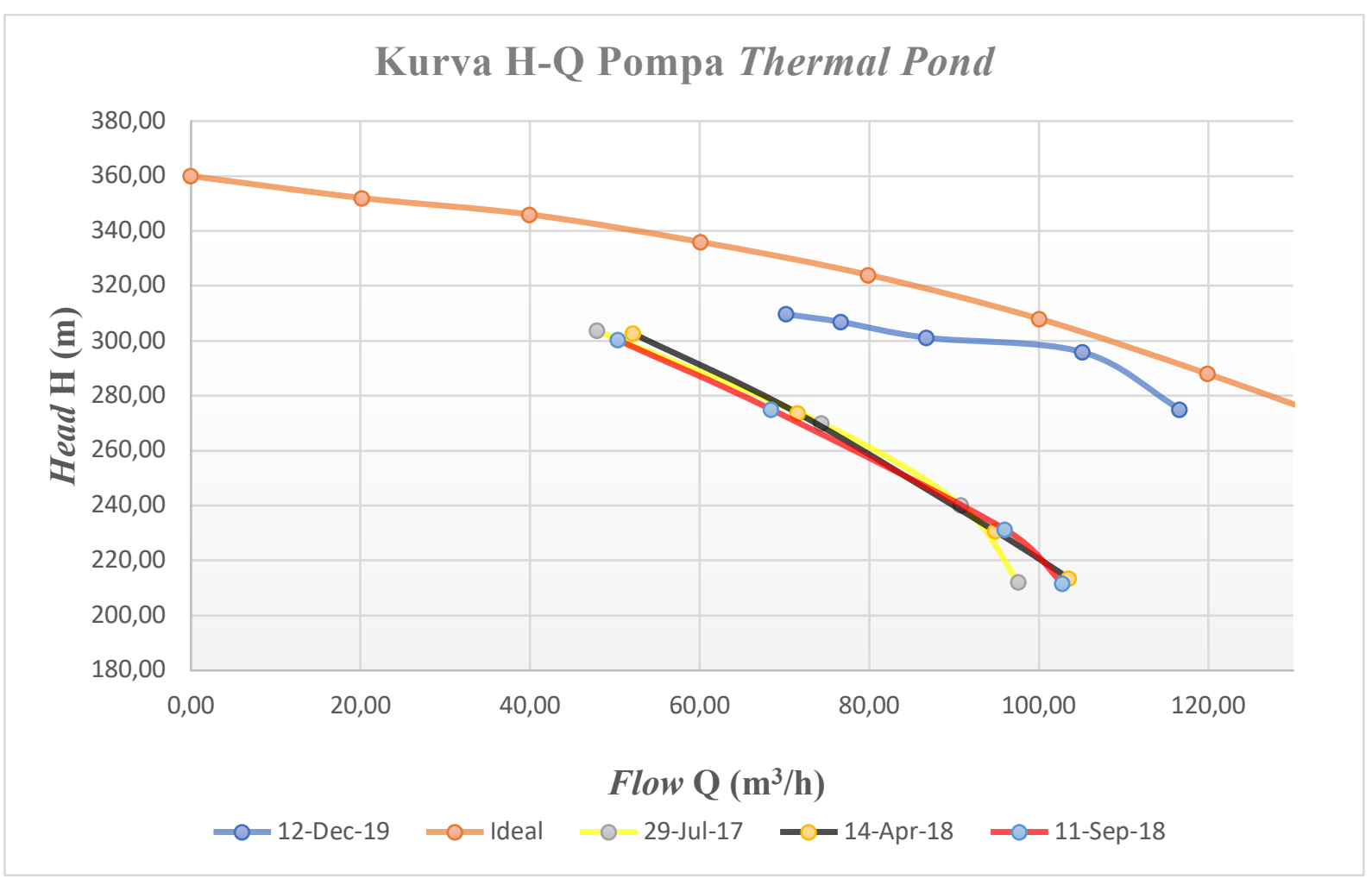

Gambar 8. Kurva karakteristik H-Q 


\section{KESIMPULAN}

Standar ISO 9906-2012 dapat diterapkan pada pengujian lapangan pompa sentrifugal dengan menyesuaikan beberapa kondisi seperti yang tercantum pada standar tersebut. Panjang instalasi perpipaan, banyaknya sambungan (fitting), kondisi permukaan dalam pipa perlu diperhitungkan untuk menemukan nilai head total. Dari data pengujian saat ini debit maksimum yang dapat dicapai pompa yaitu $116 \mathrm{~m}^{3} / \mathrm{jam}$ pada head $275,13 \mathrm{~m}$. Jika dibandingkan dengan data spesifikasi debit pompa yaitu 108 $\mathrm{m}^{3} / \mathrm{jam}$. kurva H-Q yang terbentuk dari hasil pengujian pada tahun 2019 berdasarkan ISO 9906-2012 dibandingkan dengan kurva H-Q pengujian sebelumnya terlihat garis kurva pengujian tahun 2019 lebih mendekati kurva kondisi ideal pompa. Hasil pengujian pompa sebelumnya kurva H-Q terbentuk pada area yang hampir sama dan terletak lebih jauh dari kurva ideal pompa. Berdasarkan garis kurva hasil beberapa pengujian pompa pada Gambar 8, penerapan standar ISO 9906-2012 dapat memberikan informasi unjuk kerja actual pompa, pada penelitian ini hal tersebut ditandai dengan letak garis kurva H-Q yang mendekati kondisi ideal pompa. Untuk menjaga hasil pengujian unjuk kerja pompa tetap baik, maka kondisi jalur perpipaan harus diperhatikan dengan baik untuk menghindari adanya kebocoran yang berpotensi pada kesalahan pengukuran parameter. Prosedur saat ini dapat dilakukan harmonisasi dengan prosedur standar ISO 9906 dengan tujuan validitas hasil pengujian dapat lebih diakui.

\section{Daftar Notasi}

$p \quad=$ Tekanan [atm, $\mathrm{N} / \mathrm{m}^{2}$, Bar]

$T=$ Suhu $\left[{ }^{\circ} \mathrm{C}\right]$

$N_{s} \quad=$ Kecepatan spesifik

$n \quad=$ Putaran pompa $[\mathrm{rpm}]$

$Q \quad=$ Kapasitas aliran $\left[\mathrm{m}^{3} / \mathrm{s}\right]$

$H \quad=$ Head total pompa $[\mathrm{m}]$

$A \quad=$ Luas penampang $\left[\mathrm{m}^{2}\right]$

$D=$ Diameter pipa $[\mathrm{m}]$

$R e=$ Bilangan Reynold

$V \quad=$ Kecepatan aliran rata-rata dalam pipa $[\mathrm{m} / \mathrm{s}]$

$\mu \quad=$ Viskositas cairan $\left[\mathrm{N} . \mathrm{s} / \mathrm{m}^{2}\right]$

$v \quad=$ Viskositas kinematik zat cair $\left[\mathrm{m}^{2} / \mathrm{s}\right]$

$f \quad=$ Faktor gesekan

$h_{f} \quad=$ Rugi-rugi mayor [m]

$\gamma \quad=$ Berat spesifik cairan $\left[\mathrm{N} / \mathrm{m}^{2}\right]$

$\rho \quad=$ Massa jenis air $\left[\mathrm{kg} / \mathrm{m}^{3}\right]$

$g \quad=$ Percepatan gravitasi $\left[9,807 \mathrm{~m} / \mathrm{s}^{2}\right]$

$K_{L} \quad=$ Koefisien tahanan

$P_{a m b}=$ Tekanan udara lingkungan $\left[\mathrm{N} / \mathrm{m}^{2}\right]$

$Z_{d} \quad=$ Beda ketinggian sisi discharge $[\mathrm{m}]$

$P_{v} \quad=$ Tekanan jenuh fluida $\left[\mathrm{N} / \mathrm{m}^{2}\right]$

\section{DAFTAR PUSTAKA}

[1] M. Azis, "Perancangan Siklus Rankine Organik Untuk Pemanfaatan Gas Buang Pada PLTU di Indonesia," J. Rekayasa Hijau, vol. I, no. 2, Jul. 2017, Accessed: Dec. 22, 2020. [Online]. Available: https://ejurnal.itenas.ac.id/index.php/rekayasahijau/article/view/1638.

[2] W. Hdayat, J. Waluyo, and K. Jaelani, "Perbandingan Unjuk Kerja Tangki Penyimpan Energi Termal Stratifikasi Dengan Variasi Diameter Difuser," Jun. 2015.

[3] W. Hidayat, "KARAKTERISASI DAN VISUALISASI UNJUK KERJA TANGKI PENYIMPAN ENERGI TERMAL STRATIFIKSI DENGAN VARIASI BENTUK DIFUSER,” UNIVERSITAS GADJAH MADA, 2016.

[4] (BPPT) Badan Pengkajian dan Penerapan Teknologi, "INDONESIA ENERGY OUTLOOK 2014 : Pengembangan Energi untuk Mendukung Program Substitusi BBM,” 2014. Accessed: Dec. 22, 2020. [Online]. Available: https://www.bppt.go.id/.

[5] R. Bertani, "Geothermal Power Generation in the World - 2010-2015 Update Report," in Proceedings 
World Geothermal Congress, 2015, pp. 19-25.

[6] M. Pramuda, M. Ridwan, and I. Maulana, "Optimasi Siklus Kalina KCS34 Pada Pemanfaatan Sumber Air Panas (Natural Hot Spring) Sebagai Pembangkit Listrik,” J. Rekayasa Hijau, vol. 1, no. 1, 2017, Accessed: Dec. 22, 2020. [Online]. Available: https://ejurnal.itenas.ac.id/index.php/rekayasahijau/article/view/1336.

[7] D. D. peer and V. G. Gunjalli, "Analytical Study of Performance of a Centrifugal Pump for Different Operating Conditions," Int. J. Eng. Trends Technol., vol. 54, no. 3, pp. 175-179, 2017, doi: 10.14445/22315381/ijett-v54p225.

[8] M. E. Qazizada and E. Pivarčiová, "Axial flow pump characteristics and reliability analyses at different frequency rotation," Manuf. Technol., vol. 17, no. 4, pp. 555-561, 2017, doi: 10.21062/ujep/x.2017/a/1213-2489/mt/17/4/555.

[9] E. Grist and R. P. Hentschke, "The Verification of Centrifugal Pump Performance Guarantees by Acceptance Tests-A Statistical Method," in Proceedings of the Institution of Mechanical Engineers, Part A: Journal of Power and Energy,204(02), 1990, pp. 99-108, doi: https://doi.org/10.1243/PIME_PROC_1990_204_015_02.

[10] I. J. Karassik, J. P. Messina, P. Cooper, and C. C. Heald, Pump Handbook Third Edition, Third. New York: McGraw-Hill, 2001.

[11] B. R. Munson, D. F. Young, and T. H. Okiishi, “Mekanika Fluida Jilid 1,” PENERBIT ERLANGGA, JAKARTA, 2004. 